\title{
Los Parques Culturales de Aragón
}

Ma Ángeles Hernández Prieto, Abigail Pereta Aybar, D. G. de Patrimonio Cultural. Dpto. de Educación, Cultura y Deporte del Gobierno de Aragón

Los parques culturales

\section{se conciben}

fundamentalmente

como herramientas de

gestión

extraordinariamente

próximas a criterios de

ordenación del

territorio
La evolución del concepto de patrimonio y su incorporación, de forma generalizada, al elenco de recursos económicos, ha dado lugar a que la gestión del patrimonio se plantee nuevas fórmulas de optimización de los recursos y sobre todo de coordinación de iniciativas de diferentes signos.

Por otra parte, la aceptación del medio físico como determinante importante de la producción del hombre, y por tanto del patrimonio, y la formulación de normativa legal en la cual el medio natural deviene en patrimonio, conllevan que la gestión de éste tienda hacia lo territorial sin detrimento de lo monumental (entendido como bien individual), sino más bien como estrategia complementaria.

En este sentido, Aragón, debido a sus características patrimoniales, territoriales y demográficas, ha generado una figura legal denominada Parque Cultural, regulada por la Ley 12/1997, de 3 de diciembre, de Parques Culturales de Aragón, con la idea de contar con una herramienta eficaz tanto para la conservación, protección y difusión del patrimonio como para el desarrollo sostenible del ámbito rural aragonés, que a su vez suponía la consolidación y regulación de una realidad preexis- tente y en la cual ámbitos, tan aparentemente alejados, como la investigación académica y la iniciativa local, habían sido capaces de aunar intereses y esfuerzos para preservar el patrimonio cultural (inicialmente en torno al Arte Rupestre Prehistórico, para incorporar, posteriormente, cualquier manifestación cultural reconocida en el territorio), en beneficio de las poblaciones directamente vinculadas con la presencia de estos patrimonios.

En cuanto a la denominación de Parque Cultural, hasta la reciente aprobación de la nueva Ley del Patrimonio Histórico de Andalucía, Aragón era la única Comunidad Autónoma que tenía legislación al respecto.

¿Qué es un parque cultural?

Un parque cultural es un espacio delimitado, con valores culturales y naturales, relacionados en un inventario de recursos, que pretende el desarrollo de su territorio de forma integral e integrada, con órganos de gestión propios (que implican a municipios, asociaciones y Gobierno de Aragón) y con la obligación de desarrollar un plan, conteniendo no sólo el diagnóstico del territorio sino todas 

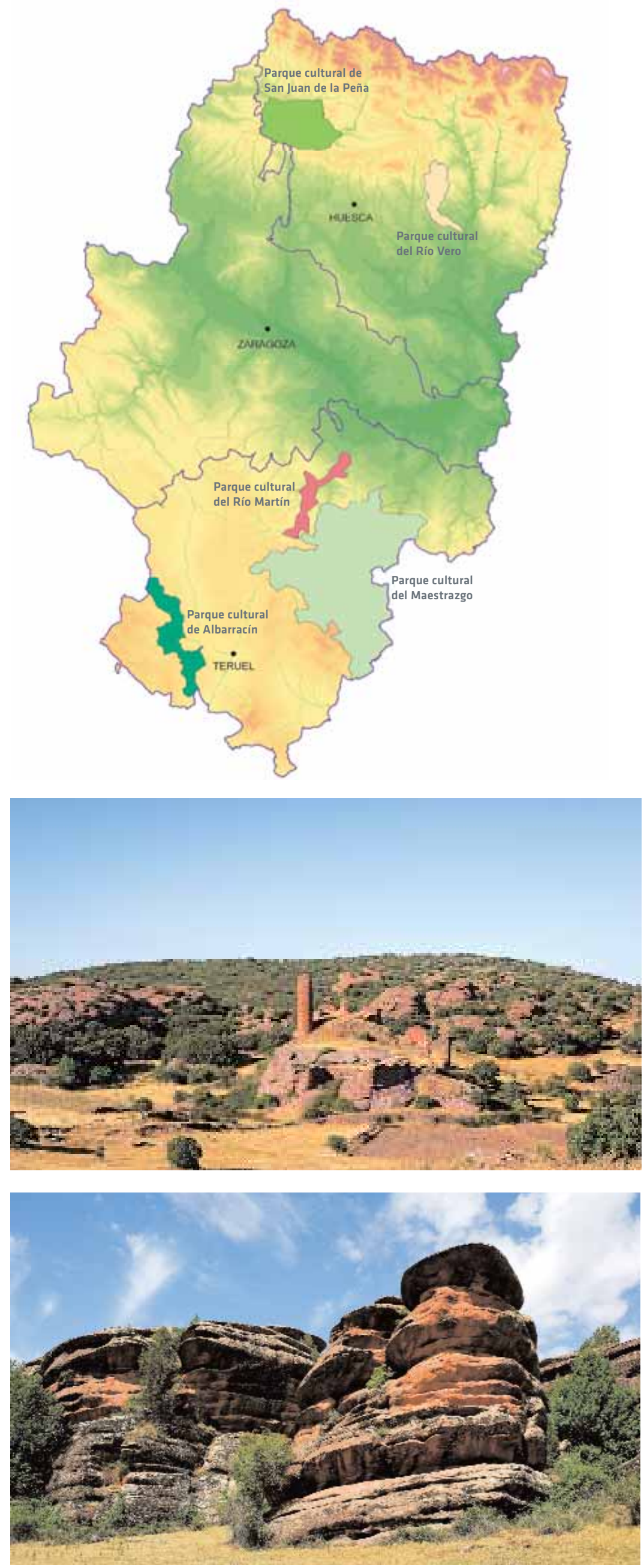

Castillo de Losares. Pozondón. Parque Cultural de Albarracín (Teruel)

๑ Abrigo de la Masada de Ligros. Parque Cultural de Albarracín (Teruel) 
las actuaciones a realizar en el parque, de forma semejante a los planes de usos y gestión que son habituales en los espacios naturales protegidos.

Si bien los parques culturales parten del reconocimiento del potencial que el patrimonio tiene como recurso en el desarrollo de los territorios, se conciben fundamentalmente como "herramientas de gestión", extraordinariamente próximas a criterios de ordenación del territorio, tal como se expone en sus objetivos, con especial atención a la población directamente vinculada al territorio del parque y a la mejora de la calidad de vida de ésta.

El parque cultural no constituye en sí una figura de protección. Para los elementos relevantes del patrimonio cultural y natural que deban ser protegidos de forma individualizada, se procederá en función de 10 establecido en las correspondientes legislaciones sectoriales.

De hecho, y en palabras de Fernando López Ramón, "los Parques Culturales pudieran llegar a ser importantes instrumentos de Ordenación del Territorio, dotados de mayores posibilidades de eficacia que los complejos instrumentos globales" (LÓPEZ RAMÓN, F. Reflexiones sobre la indeterminación y amplitud del Patrimonio Cultural. Revista Aragonesa de Administración Pública, №15, 1999, p. 215).

Como se puede ver en la definición que la ley ha establecido para el parque cultural, en su ámbito se pretende el desarrollo de políticas integradas, tanto territoriales como sectoriales, con especial incidencia en las de patrimonio cultural y natural, el fomento de la actividad económica, turismo rural, infraestructuras y equipamientos; todo ello a través de la coordinación interadministrativa, del propio Departamento de Educación, Cultura y Deporte con otros departamentos del Gobierno de Aragón y de éstos con ayuntamientos, comarcas, asociaciones y particulares.
Aragón cuenta en este momento con cinco parques culturales, los cuales ya se enunciaban en la propia ley: Parque Cultural de San Juan de la Peña y Parque Cultural del Río Vero en la provincia de Huesca y Parque Cultural del Río Martín, Parque Cultural del Maestrazgo y Parque Cultural de Albarracín, en la provincia de Teruel.

A esto habrá que añadir en breve una nueva iniciativa en torno al patrimonio industrial y que, bajo la denominación de Parque Cultural de Sierra Menera también en la provincia de Teruel, agrupa a varios municipios vinculados a la explotación metalúrgica, la cual está documentada en el territorio desde época romana.

La fórmula de gestión de estas entidades está organizada en tres niveles: un patronato, órgano colegiado, consultivo y de participación, en el que están representados todos los municipios con territorio incluido en el parque y que hayan suscrito un compromiso con el Gobierno de Aragón referido a la financiación del parque, los Departamentos del Gobierno de Aragón con competencias en Economía, Medio Ambiente, Ordenación del Territorio, Turismo y naturalmente Patrimonio Cultural, este último con una representación más alta y, por último, hasta cinco representantes de entidades públicas o privadas cuyos objetivos estén directamente relacionados con los del parque y su territorio. En este sentido se ha procurado que a este órgano se adhieran no sólo entidades de carácter cultural sino también todas aquellas asociaciones de carácter económico que favorecen el desarrollo socioeconómico del territorio.

En segundo término existe un Consejo Rector, como órgano ejecutivo, compuesto por tres representantes de los municipios integrantes del parque, tres representantes del Gobierno de Aragón, de los cuales dos corresponden a Patrimonio Cultural y el Gerente del parque.

Este Gerente es el tercer nivel de la gestión, órgano unipersonal directamente responsable de la ejecución de los programas y de la 
( Casa de la Julianeta, Albarracín. Parque Cultural de

Albarracin (Teruel)

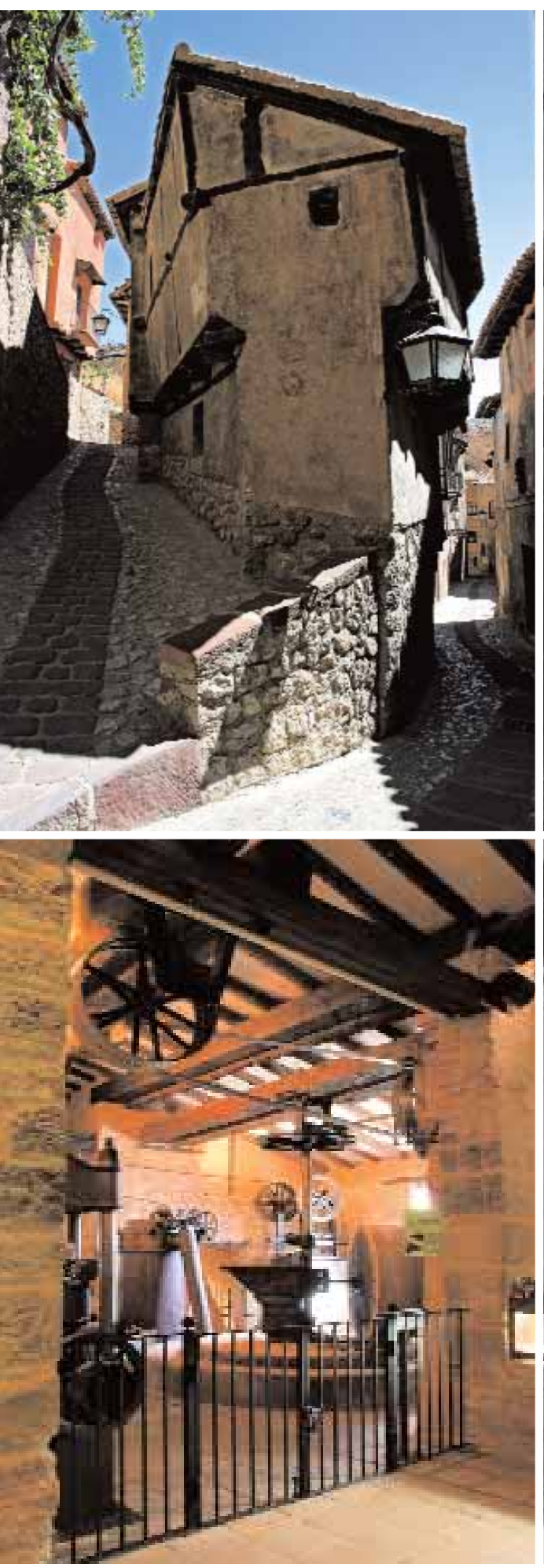

$\checkmark$ Puerta de acceso a la Iglesia parroquial. Pozondón. Parque

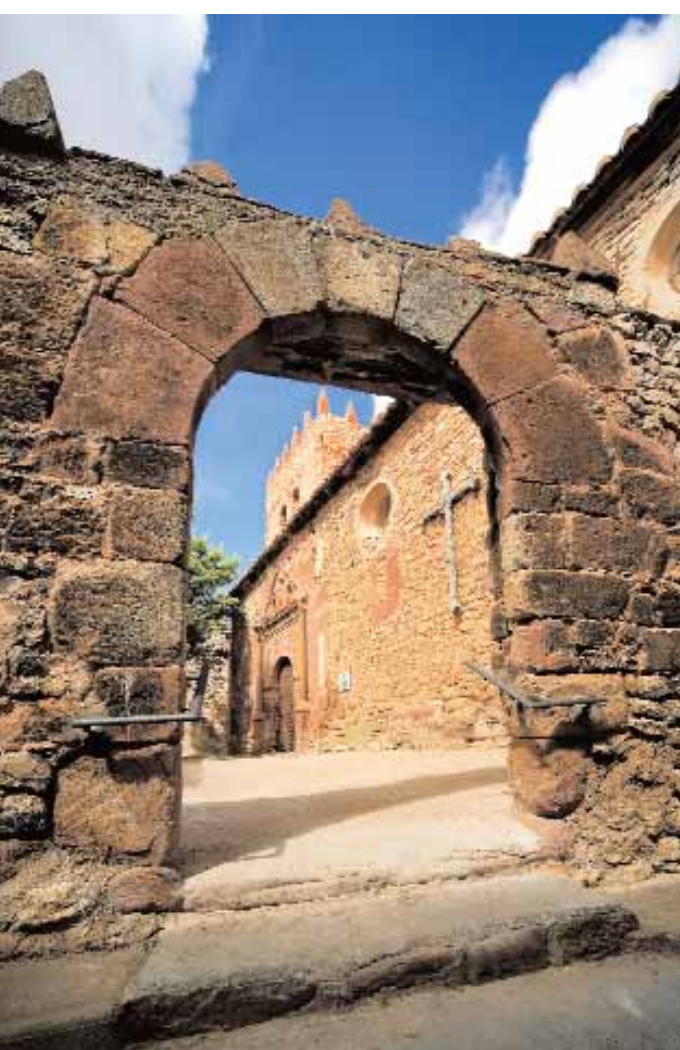

(- Calle de la Catedral, Albarracín. Parque Cultural de

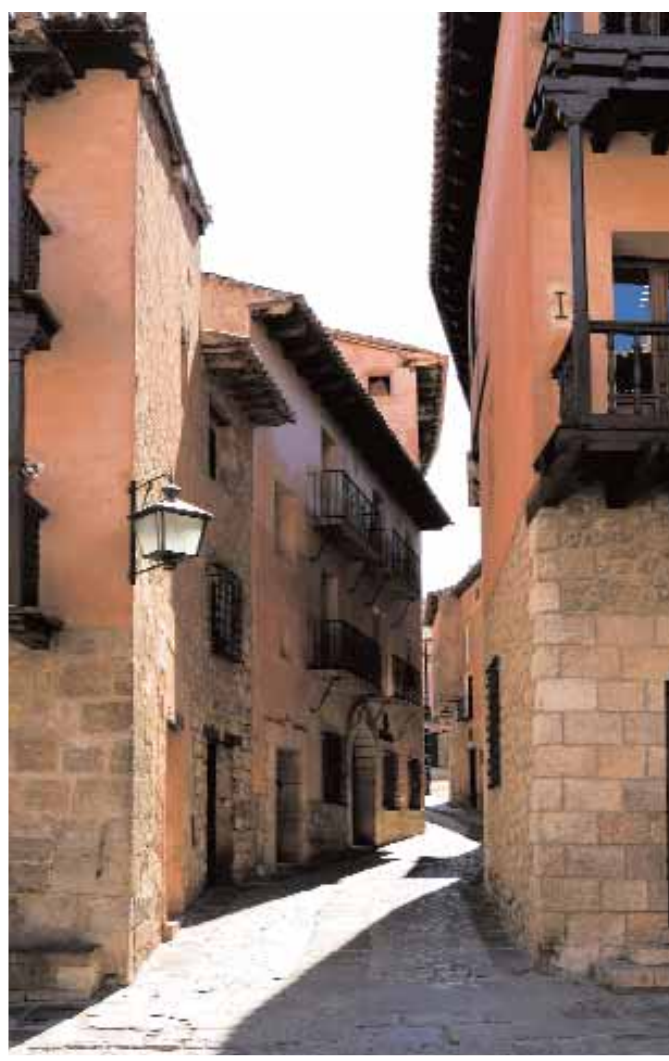

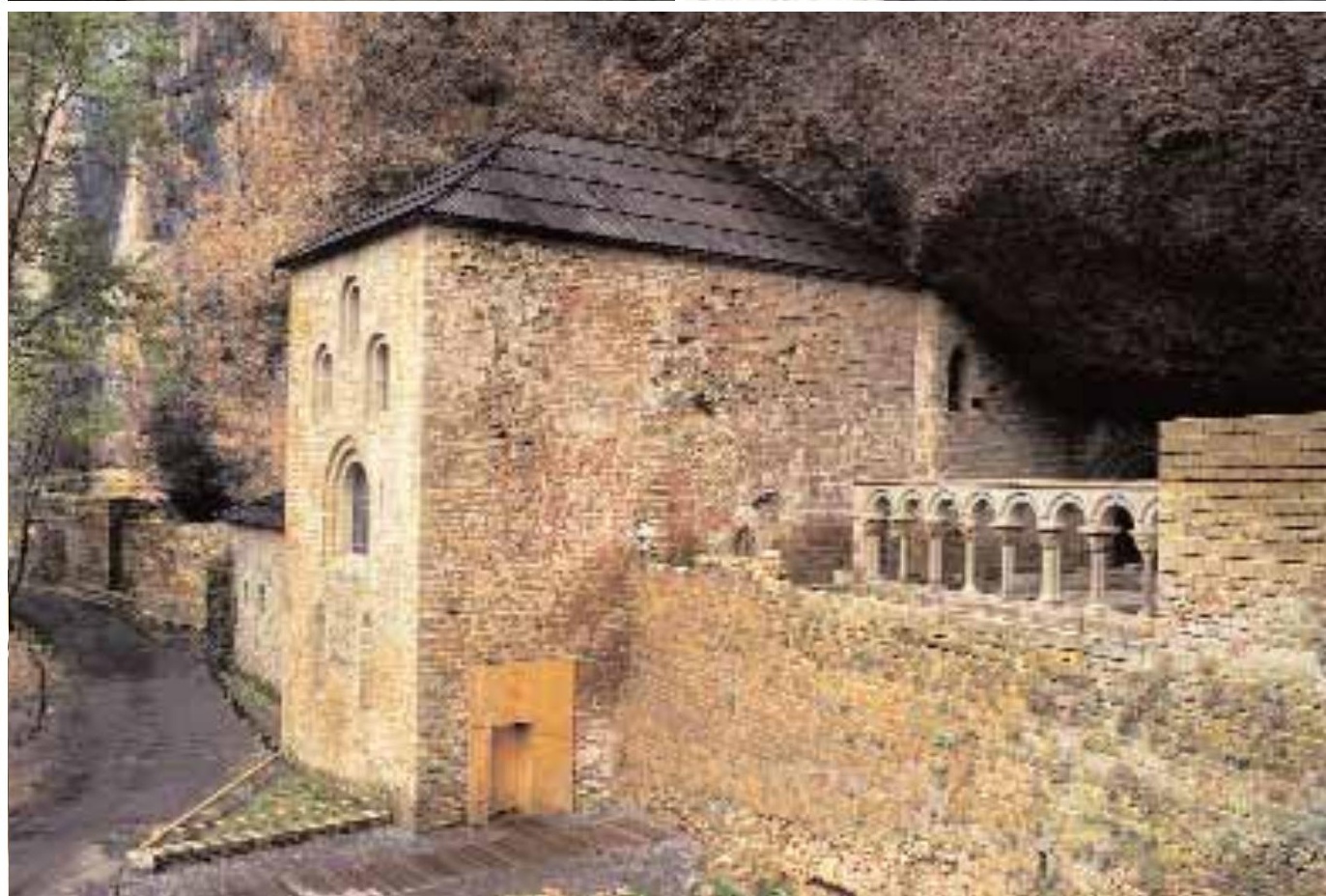

(1) Monasterio San Juan de La Peña, en Bárcabo. Parque Cultural de San Juan de la Peña (Huesca) 


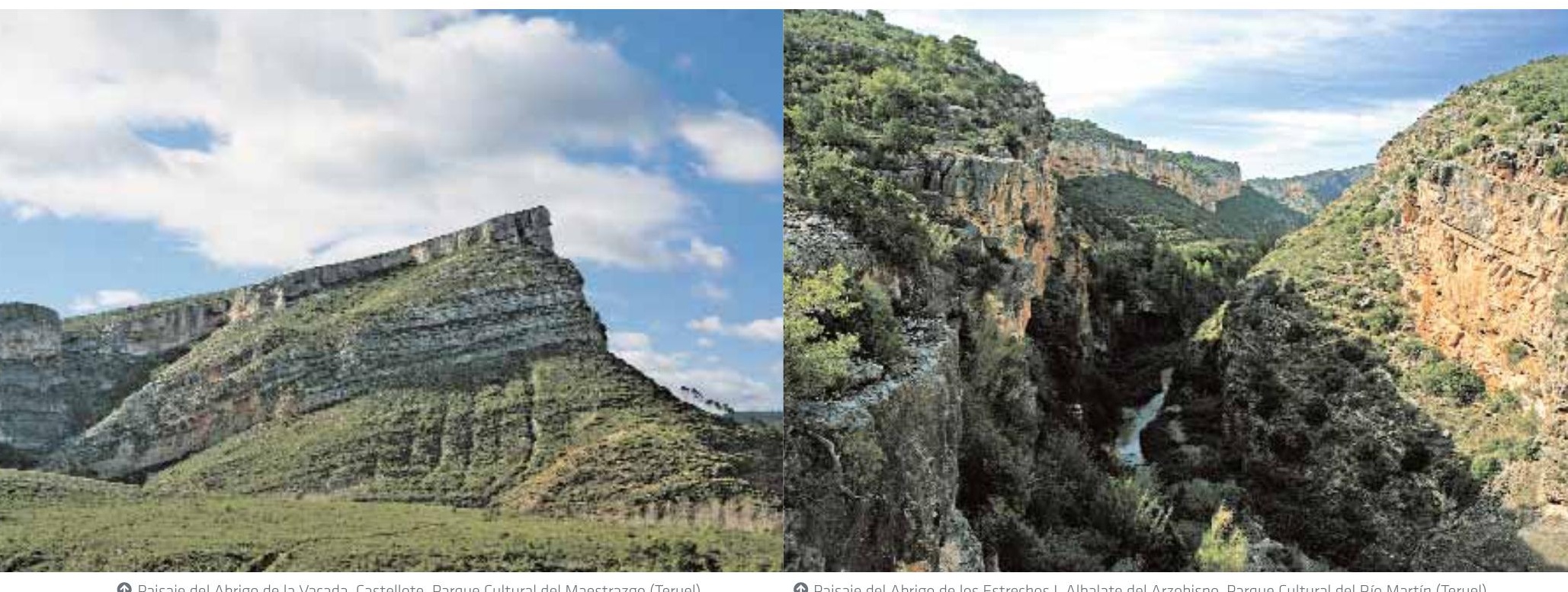

(1) Paisaje del Abrigo de la Vacada, Castellote. Parque Cultural del Maestrazgo (Teruel)

(1) Paisaje del Abrigo de los Estrechos I, Albalate del Arzobispo. Parque Cultural del Río Martín (Teruel)

coordinación de las diferentes acciones que afecten al territorio parque. En este sentido la figura del Gerente es fundamental, por cuanto es el agente directo sobre la zona. Por ello, se ha promovido sistemáticamente que dicha gerencia se encomiende a personas estrechamente vinculadas con el territorio, profesional y personalmente, de forma que la implicación en el proyecto sea completa y por otra parte sea percibido por la población como uno más.

Hay que señalar que, si bien se pretende que la gestión del parque cultural sea prioritariamente local, los parques culturales no tienen personalidad jurídica propia y están directamente vinculados al Gobierno de Aragón, sin menoscabo de que se puedan suscribir convenios y acuerdos, con otras entidades públicas o privadas, para el desarrollo de diferentes tareas, como puedan ser algunas de gestión 0 la ejecución de proyectos concretos.

En este sentido la ordenación territorial de Aragón en comarcas ha supuesto la aparición de una administración local nueva de carácter supramunicipal, que en muchos casos está respaldando con gran solvencia el trabajo en los parques culturales, aunque todos los de Aragón integran territorios pertenecientes a varias comarcas, por lo que constituyen competencia exclusiva del Gobierno de Aragón. Cabe mencionar, como ejemplo, a la Comarca del Somontano de Barbastro, cuyas inquietudes sobre el patrimonio ya se pusieron de manifiesto antes de su constitución, puesto que existía una agrupación de ámbito semejante como Mancomunidad, y que en la actual andadura no sólo ha reforzado el trabajo en el Parque Cultural de Río Vero, sino que además ha trasladado en parte el modelo de actuación sobre patrimonio, inicialmente aplicado en el parque, al resto del territorio comarcal con excelentes resultados.

Esta misma colaboración se ha ido desarrollando, en diferentes grados, en el resto de los parques culturales, cooperando las comarcas en acciones e inversiones coordinadas desde el parque y cuyos resultados benefician a todo el conjunto, como las cartillas didácticas del Parque Cultural del Río Martín, la contratación y mantenimiento de oficinas de la Gerencia del Parque Cultural de San Juan de la Peña, la ejecución e itinerancia 


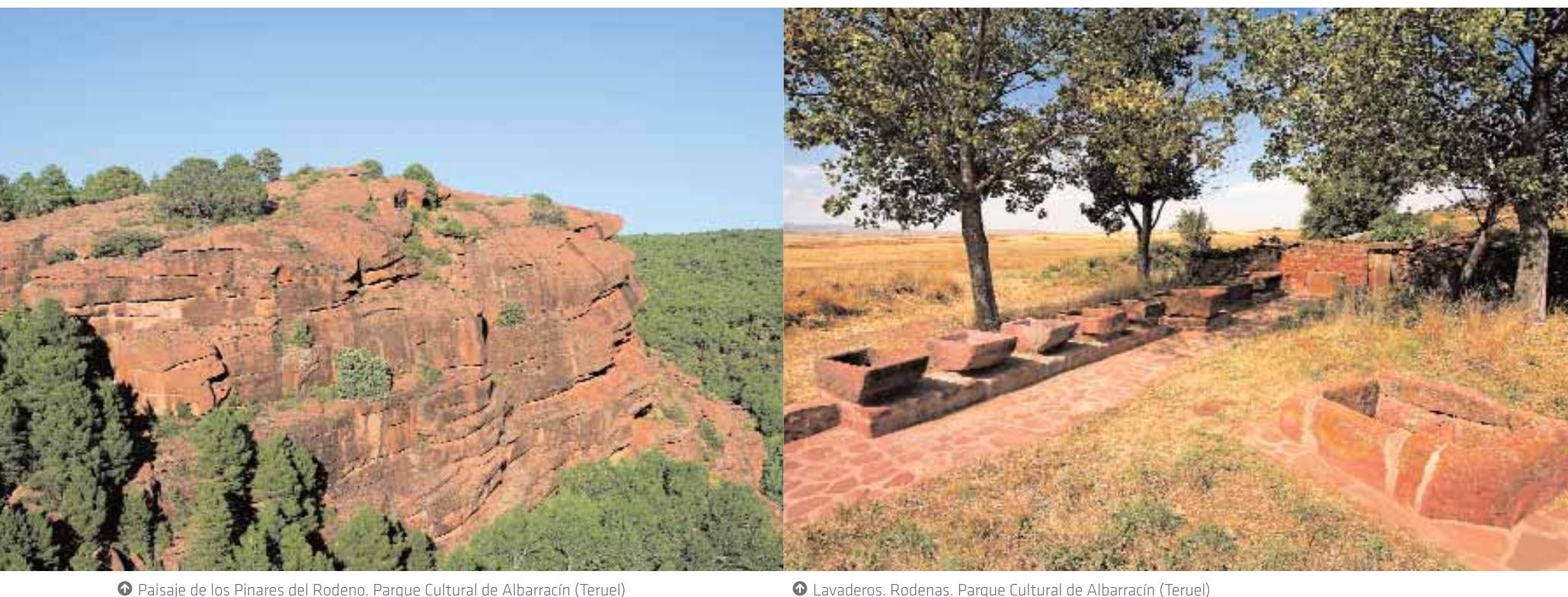

de exposiciones en el Parque Cultural del Maestrazgo o el apoyo a señalizaciones en el Parque Cultural de Albarracín.

La financiación de buena parte de las actuaciones, tanto de mantenimiento como de inversión, que se han llevado a cabo en los parques culturales aragoneses, se ha realizado a través de subvenciones así como de inversión directa del Gobierno de Aragón, dentro de diversos proyectos europeos (FEDER, objetivo 2, Interreg IIIB, y FSE).

Los criterios de actuación en estos territorios han seguido dos líneas argumentales básicas: por una parte la intervención en el patrimonio cultural en cuanto que recurso transformable en producto a integrar en una oferta cultural, y por otra en la generación de equipamientos e infraestructuras de servicios de las que carecían los municipios afectados, con el objetivo de que, una vez creadas, sean gestionadas, en la medida de lo posible, por la iniciativa privada, a fin de proporcionar expectativas laborales en la propia población, por ejemplo albergues, alojamientos de turismo rural, centros de interpretación, zonas de acampada, redes de senderos con su correspondiente mantenimiento.
Estas medidas se han complementado con acciones formativas, dirigidas a los guías y monitores del parque, a fin de mejorar los servicios de atención al público en los enclaves y equipamientos culturales al tiempo que se consolidan y actualizan las habilidades de este colectivo. Al mismo tiempo y específicamente dirigida a la población local, en general, y a aquellos que desarrollan una actividad relacionada con el sector servicios, en particular, tales como viviendas de turismo rural, bares $y$ restaurantes, establecimientos de artesanía y empresas de ocio vinculadas a la naturaleza (senderismo, rafting, escalada, espeleología..), se han desarrollado diversos cursos destinados a incorporarlos al tejido divulgativo del parque y sus contenidos.

La norma que regula los parques culturales aragoneses contempla, como se ha dicho, la elaboración de un plan de cada uno de ellos, como instrumento de planificación, que priorizando la protección del patrimonio cultural, procure la coordinación de los instrumentos de la planificación urbanística, ambiental turística y cultural. Entre sus objetivos, si bien aparecen bien definidos los referidos a la protección del patrimonio cultural, hay dos espe- 
(1) Abrigo del Torico del Pudial, Ladruñán. Parque Cultural del Maestrazgo (Teruel)

( Paisaje de los Cañones del Río Vero. Parque Cultural de Río Vero (Huesca)

(- Centro de Interpretación de Arte Rupestre, Colungo. Parque Cultural del Río Vero (Huesca)
(4)

( Mirador de los Cañones del Río Vero. Parque Cultural del Río Vero (Huesca)

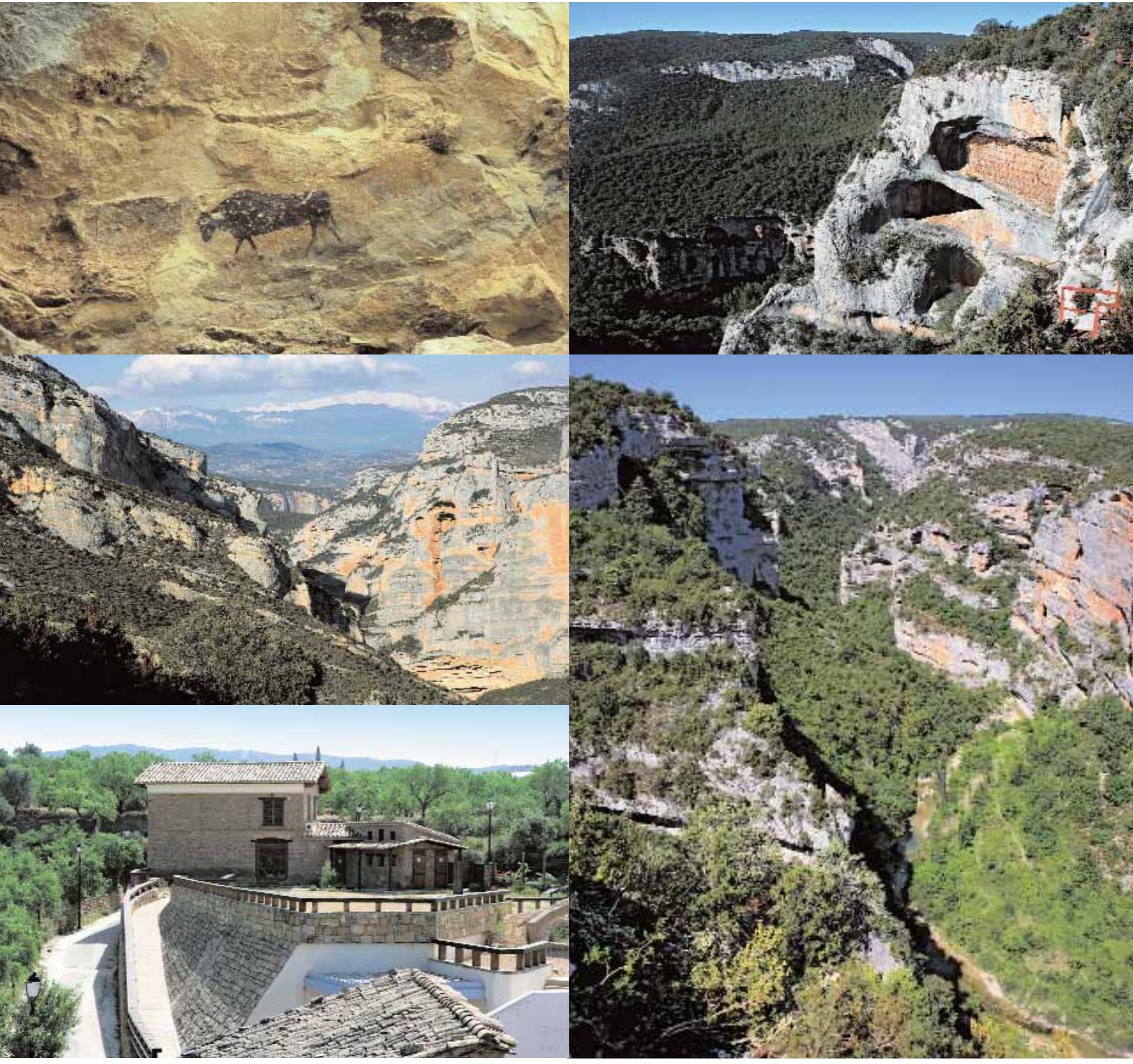


cialmente relevantes en lo que atañe al desarrollo socioeconómico:

$\rightarrow$ Fomentar la acción cultural y la actividad económica en términos de desarrollo sostenible, señalando las actividades compatibles con la protección del patrimonio.

$\rightarrow$ La promoción del turismo cultural y rural.

En este sentido el plan del parque adquiere una dimensión más amplia que la meramente patrimonial o cultural, ya que este documento debe ser informado inicialmente, tanto por la Comisión Provincial de Patrimonio Cultural, como por la Comisión Provincial de Ordenación del Territorio correspondiente. La aprobación definitiva corresponde al Consejo de Gobierno de Aragón, previo informe del Consejo de Orde- nación del Territorio de Aragón, siendo obligado el cumplimiento de las directrices establecidas en el documento para todas las instancias implicadas en el territorio parque, sean públicas o privadas.

En definitiva, el modelo de los parques culturales aragoneses se ha revelado como un eficaz instrumento de desarrollo y promoción de algunos territorios desfavorecidos, básicamente a través del patrimonio cultural sin detrimento de políticas de desarrollo económico. Asimismo, en el plano social el resultado más significativo es la toma de conciencia por parte de la población local de su propia identidad, del valor de su historia a través del patrimonio conservado y el fortalecimiento de su propia autoestima.

\section{Nota}

Imágenes pertenecientes al Archivo del Gobierno de Aragón. Autores de las imágenes: Columna Villarroya y Armando Llamazares

\section{En la web}

Red Andaluza de Yacimientos Arqueológicos

www.juntadeandalucia.es/cultura/web/publico/areas/minisitio.jsp?idA=5\&men=9\&pagc=5_3EspaciosCulturales.jsp

Sección de la Web de la Consejería de Cultura de la Junta de Andalucía con un espacio dedicado a la Red Andaluza de Yacimientos Arqueológicos. Además de la información del proyecto, permite consultar una ficha con información de los bienes que integran la Red.

\section{Ruta Dolménica de Huelva}

www.juntadeandalucia.es/averroes/gabinetes/contentimage/html/hu/webrutamegalitica/

La página ofrece información sobre los distintos Conjuntos Dolménicos que configuran la ruta y sobre el Centro de Interpretación de la Cultura Dolménica creado, incluyendo fotografías y planos de los recintos. Dispone de un interesante y práctico apartado dedicado a Enlaces y Bibliografía. Parte del valor de esta Web radica, además de en sus contenidos específicos, en la escasez de rutas o redes culturales que disponen de un acceso Web unificado a todos sus elementos.

Webs de los Conjuntos Arqueológicos y Monumentales de Andalucía

www.juntadeandalucia.es/cultura/web/publico/areas/minisitio.jsp?idA=108men=116pagc=10_4_0presentacion.jsp

La Web de la Consejería de Cultura de la Junta de Andalucía dispone de este enlace, a través del cual se puede acceder a las Webs de cada uno de los Conjuntos Arqueológicos y Monumentales dependientes de esta Consejería. A través de un menú prácticamente idéntico y con formas de navegación semejantes, ofrecen información sobre sus servicios, posibles recorridos, exposiciones y, en algunos casos, presentan la posibilidad de realizar una visita virtual al conjunto. 